\title{
Explaining Ethnicity: Primordialism vs. Instrumentalism
}

\author{
Dr. Shyamal Kataria \\ Department of International Relations, \\ University of Sharjah, Sharjah, UAE
}

\begin{abstract}
Ethnicity, very much like gender, has long been viewed an inescapable facet of our social reality. All humans have an ethnicity, or at least are ascribed one throughout of lives. As such, there is a huge amount of scholarly intrigue attached to ethnicity from across both the biological and social sciences. In this respect, much of the focus has been on explaining how and why ethnicities form and persist through time. Two principal schools of thought on ethnicity are primordialism and instrumentalism. This article aims to impartially review and, where possible, scrutinise both perspectives in an attempt to arrive at a more precise and considered understanding of ethnicity.
\end{abstract}

Keywords: Ethnic, Ethnicity, Identity, Primordialism, Instrumentalism

\section{INTRODUCTION}

Ethnicity, very much like gender or sex, has long been viewed an inescapable facet of our social reality. All humans have an ethnicity, or at least are ascribed one throughout of lives. Yet, unlike gender, ethnicity has often been used to justify conflict, both violent and non-violent, with outgroups and internal belligerents that supposedly threaten its existence and/or vitality. As such, and unsurprisingly, there is a huge amount of scholarly intrigue attached to ethnicity from across both the biological and social sciences. In this respect, much of the focus has been on attempting to theorise how and why ethnicities form and persist through time. Two principal schools of thought on ethnicity are primordialism and instrumentalism. Regarded as opposites of sorts, primordialism interprets ethnicity as naturally, or at least organically, formed through time, whereas instrumentalism perceives ethnicity in principally rational, topdown, terms. This article aims to impartially review and, where possible, scrutinise both perspectives in an attempt to arrive at a more precise and considered understanding of ethnicity.

\section{PRIMORDIALISM}

Primordialism regards ethnicity as naturally, or at least organically, formed through time. Much of the early primordialist discourse, generated by nationalists themselves, can be accused of lacking sophistication and, very often, factual basis. However, in recent decades, this school of thought has yielded two notable perspectives that have served to give it far more credence than it had held before. These perspectives consist of sociobiological primordialism and cultural primordialism respectively.

\section{Primordialism: Sociobiological perspective}

The foundational contribution to sociobiological primordialism is associated with the work of Peter Van den Berghe (1978, 1988, 1995, and 2001). Van den Berghe, following a near neoDarwinian line, describes ethnic groups as 'population[s] bounded by the rule or practice of endogamy' (1988: 256), which, he argues, is driven by a shared belief in the uniqueness of the group and thus a primordial desire to maintain its 'purity'. While claims to pre-existing purity would appear dubious to those sceptical of the primordialist line, Walker Connor, by no means 
sympathetic to this school, correctly points out, while referring to ethnic nations, that it is 'the sense of unique descent' which is crucial to understanding group formation and persistence (1994: 202). While it is difficult to argue with Connor here, it must be said that consciousness of this uniqueness is very much contextually governed. To demonstrate this point, we can quote a White Afrikaner minister of religion in apartheid South Africa who, speaking on the topic of 'coloured people', remarked,

here we have a people who came into being through miscegenation with the Whites. And as a mongrel race, they are, to us, the writing on the wall, a warning against what can happen with intermixtures. They are Western in their code of living. They speak our language, sing our songs, live in our country, but they are a people notorious for their moral corruption. Lies are to them second nature. They are absolutely unreliable in any matter, have little ambition and get their greatest pleasure from a bottle of wine and debauchery [emphasis added] (The Star, 1961).

In this respect, the birth of mixed race people represent the consequences of what can occur if the rigidity of group boundaries are not adhered. Not only is it an intergenerational corruption of what otherwise should naturally occur, but this 'new hybrid' racial/ethnic groups that are produced through miscegenation are nearly always regarded as inferior.

While many ethnicities are bound together, as in the White Afrikaners of South Africa during Apartheid, on the basis of what they are not, it is perhaps more troublesome to agree on what actually constitutes an ethnic group, and what it is that gives them their uniqueness. For even the most ethnically homogenous groups would find it virtually impossible to conclusively demonstrate that its members share one or a set of genetic/physical traits that are exclusive to them alone. According to Connor, 'it is not chronological or factual history that is the key to the [group], but sentient or felt history', meaning 'all that is irreducibly required for the existence of a [group] is that the members share an intuitive conviction of the group's separate origin and evolution' (1994: 202). While it is difficult to disagree with Connor's analysis here on the role of subjectivity in affixing group boundaries, he falls short of explaining why such a belief develops in the first place. For rationalist scholars this belief would be attributed either to the results of elite manipulation and/or the self-interest of the group members themselves (e.g. Brass 1979, 1991; Olson 1965); however, this still does not account for why some individuals coalesce into a group and others not. Writing a year after Connor, Van den Berghe clarifies his stance on the issue by suggesting that claims to unique descent

will only be believed if members of an ethnic group are sufficiently alike in physical appearance and culture, and have lived together and intermarried for a sufficient period (at a minimum three or four generations) for the myth to have developed a substantial measure of biological truth (1995: 360)

As such, one can surmise that the practice of endogamy not only helps keep ethnicity intact but forms the very basis for the separate identity itself. This lends a great deal of credence to the primordialist perspective. On a side note, the sociobiological explanation may raise the question as to whether genealogical foundation, factual or otherwise, constitutes a prerequisite for a separate ethnicity. The short answer is 'no'. However, it is undeniable that genealogy is one of the more objective indicators of ethnicity. This view is shared by Donald Horowitz, who writes, 'the more visible and the closer to birth, the more immutable and therefore reliable the cue. A name can be changed, a language learned, and clothing altered, but...height [is] more difficult to undo' ([1985] 2000: 47). Therefore, it would be sensible to conclude that ethnic groups doubling-up as racial ones tend to have more substance than those that do not, and, for the most part possess somewhat more longevity. 


\section{Primordialism: Cultural perspective}

With regard to cultural primordialism, two contributions are particularly noteworthy: those made by Clifford Geertz (1973) and Steven Grosby (1994). Starting with the first, Clifford Geertz maintains that humans have primordial attachments to what he describes as the 'givens' of social existence, be it an immediate kin connection or a particular religious and/or linguistic community. He explains that

[t]hese congruities of blood, speech, custom, and so on...have an ineffable, and at times overpowering, coerciveness in and of themselves. One is bound to one's kinsman, one's neighbour, one's fellow believer, ipso facto; as the result not merely of personal affection, practical necessity, common interest, or incurred obligation, but at least in great part by virtue of some unaccountable absolute import attributed to the very tie itself. The general strength of such primordial bonds, and the types of them that are important, differ from person to person, from society to society, and from time to time. But for virtually every person, in every society, at almost all times, some attachments seem to flow more from a sense of natural-some would say spiritual-affinity than from social interaction (1973: 259-260).

In other words, he does not actually suggest that the 'givens' of social existence are primordial but only that the attachments that people have to them are. Such a claim appears quite sensible. These attachments, in Geertz's view, are deep-rooted and perhaps even inescapable to the individuals constituting the ethnic group or ethnic nation. Such an explanation would account for why so many people have such ardent attitudes about ethnicity (whether positive or negative) and often engage in seemingly inexplicable acts, including self-sacrifice, for the sake of these 'givens'. However, Geertz's view exhibits a degree of weakness when we consider that many people shift their language or convert to a different religion and thus effectively sever ties with the 'givens' that may have defined their earlier life and were, allegedly, ineffable (Smith 1997: 154). Furthermore, though Geertz's argument helps to account for why ethnic identities persist, it is less useful in addressing the question of why they are formed to begin with-thus leaving scope for others scholars, irrespective of school of thought, to do so.

Steven Grosby's work has received far less attention than that of Geertz's. One reason for this may be Grosby's insistence that the 'objects' (or 'givens', as Geertz would call them) to which members of an ethnicity attach themselves are primordial. '[E]thnic groups and nationalities exist', he argues, 'because there are traditions of belief and action towards primordial objects such as biological features and especially territorial location' (Grosby 1994: 168). While many scholars of a rationalist persuasion, of which there are no shortage in academic circles, would instinctively dismiss this view, upon closer inspection it would appear to have some credence. This is because the 'primordial objects' to which Grosby refers-biological features and territorial location-cannot, in and of themselves, be instrumentally manufactured. This is not to say that one cannot manipulate or exaggerate the extent of biological difference between groups for political ends, or that the borders of the 'imagined homeland' (Anderson 1983) are necessarily uniform in the minds of all ethnic groups-but only that both of these things exist as objective points of fact. The strength of these primordial objects help to account for the appeal of black nationalism in the United States during the 1960s and 1970s (Collins 2004), and for why so many hitherto apolitical African-Americans rallied so impressively behind the first prospective 'Black' President, Barack Obama, in 2008 and again in 2012. It also helps to explain why, in the early twentieth century, the Zionist Congress, in pursuit of a potential homeland for global Jewry, so vehemently rejected Theodor Herzl's infamous 'Uganda project'-Uganda being a territory with which they had no prior spiritual or cultural connection (Gur-Ze'ev 2003: 31). 
Of course, conceding a large degree of primordiality to objects such as biological features and territorial location does not imply that ethnic identity forms, and persists, primordially. After all, these objects constitute only two components, albeit quite significant ones, out of an indeterminate number serving to make up ethnicity at any given time. However it should be noted that even seemingly constructed components, such as language or dress, are typically imagined within the frameworks of primordiality-be it the stereotypical racial profile of the person reciting their ethnic language, or the ethnic dress worn by a person situated within the emblematic terrain of their ethnic homeland.

\section{INSTRUMENTALISM}

Instrumentalism is often viewed in diametric opposition to primordialism, which it dismisses as unscientific. Instrumentalism perceives ethnic identities in principally rational terms. There are two instrumentalist perspectives of particular value: the elite perspective and the social engineering perspective.

\section{Instrumentalism: Elite perspective}

The seminal contribution to the elite perspective comes from the work of Paul Brass (1979, 1991). Brass's work emphasises the role of elites in the formation and persistence of ethnic identity. He argues that

[e]lites and counter-elites within ethnic groups select aspects of the group's culture, attach new value and meaning to them, and use them as symbols to mobilize the group, to defend its interests, and to compete with other groups (1979: 40-41).

In attributing the ethnic identity of a group to the machinations and calculations of its elite, Brass's thesis helps to rationally account for why the masses, prisoners to the symbols that distinguish them, often engage in what appear to be, to the impartial observer at least, selfdefeating communal pursuits. Since, in such cases, elite interests are being satisfied and/or remain protected. Despite its explanatory strengths, there are limits to how far this argument allows us to stretch the instrumentalist line. As Brass himself concedes, ethnic and ethnonational identities are created through 'the selection of particular dialects or religious practices or styles of dress or historical symbols from a variety of available alternatives' (1991: 25). This suggests, first, that these identities cannot be created out of nothing: there needs to be a pre-existing artefact to build on or revive. This does not necessarily mean that such artefact needs to be primordial in nature: only that, elites, at any given time, do not enjoy free reign to formulate a group's ethnic identity. Second, from the variety of available alternatives, some, as symbols, will inevitably strike a deeper cord with the masses than others do. This is usually because such symbols, many of which possessing an esoteric value that even most elites remain unaware of, have held a deep and historic significance for the group in its past and so constitute an important component of its ethnic identity.

\section{Instrumentalism: Social-engineering perspective}

As opposed to the ad hoc top-down approach associated with the elitist perspective, the socialengineering explanation suggests that a far more systematic and official set of processes are at play during the formation, and persistence, of ethnicity. The important contributions by Eric Hobsbawm (1983) and Ernest Gellner (1983) warrant our attention in this regard. Dealing with the first of these, advancing the notion of 'invented traditions', Hobsbawm proposed that societal traditions that might appear, and which many ethnic and national groups assume to be, ancient and/or primordial are in actual fact far more recent and deliberate in origin (1983: 1). By 'invented traditions', he means

[a] set of practices, normally governed by overtly or tacitly accepted rules and of a ritual or symbolic nature, which seek to inculcate certain values and norms of 
behaviour by repetition, which automatically implies continuity with the past. In fact, where possible, they normally attempt to establish continuity with a suitable historic past' (1983: 1).

In other words, the allure of assumed historical significance, and implied continuity, associated with these 'traditions' are what give its architects, and the institutions they represent, legitimacy vis-à-vis the masses.

While Hobsbawm's contribution helps to explain, how ethnic identities are formed and persist, it fails to address the fundamental question of why people so often need to look backward, or for set precedence, in order to legitimise the present or indeed the future. Whether such behaviour is owed to something primordial in human nature or owed more to contemporary social conditioning is debateable.

For Ernest Gellner, whose work might easily be characterised as 'modernist', though speaking about the formation of the nation rather than ethnicity per se, he attributes the setting up of identity formation to the institutions of the state and, in particular, those related to education. As he puts it:

At the base of the modern social order stands not the executioner but the professor. Not the guillotine, but the (aptly named) doctorate d'etat is the main tool and symbol of state power. The monopoly of legitimate education is now more important, more central than the monopoly of legitimate violence (Gellner 1983: 34).

Using a botanical analogy, Gellner suggests that, whereas the cultures that predated the nationstate were like flora of a wild variety, national cultures needed to be specifically 'cultivated'. National cultures, he notes, 'possess a complexity and richness, most usually sustained by literacy and by specialized personnel', yet remain fragile, since they 'would perish if deprived of their distinctive nourishment in the form of specialized institutions of learning with reasonably numerous, full-time and dedicated personnel' (1983: 50).

Though Gellner's work holds great significance, especially for explaining the development of national identity in post-colonial societies that have consciously embarked upon nationbuilding exercises, it falls short of explaining the formation/persistence of ethnic identities. This is because, as mentioned previously, ethnic-nations and ethnic forces, have existed, and continue to exist, beyond the nation-state level. This is not to say that state institutions do not interact or influence the ethnic forces that exist above, or below, them: only that it can seldom 'create' these forces. As far as the persistence of ethnicity is concerned, arguably state institutions usually perform this function inadvertently by inviting an ethnic backlash from groups within it resisting policies geared at homogenisation.

\section{SUMMARY}

This article has reviewed the two principle, yet opposing, schools of thought on ethnicity, that primordialism (including sociobiological and cultural perspectives) and instrumentalism (including elitist and social engineering perspectives). These have been scrutinised to assess their strength in explaining the formation and persistence of ethnicity. Despite their respective strengths, neither school of thought can, through strict adherence to their purist lines, fully account for this phenomenon. It is sensible to assume, therefore, that ethnic identities are a product of both primordial and instrumental factors. Nonetheless, by meandering across the line between primordialism and instrumentalism, it is possible to extract a set of 'truths', that ought to hold universal relevance, and it is these which will hopefully serve as the principal 
contribution of this article to the wider debate on ethnicity. In no particular order, the universal truths of ethnicity consist of the following;

- Endogamy not only keeps ethnicity intact, but also forms the very basis of the separate identity claim itself.

- Ethnic groups that double-up as racial ones tend to have far more substantive basis than those that do not.

- People tend to have primordial attachments to the givens/objects associated with their ethnicity.

- Certain objects/givens associated with ethnicity are themselves primordial (or at least have a large primordial element to them).

- Elites often draw upon elements of a group's culture from an available set of alternatives/options to use as symbols with which to construct and/or mobilise the ethnic identity of their group.

- Societies often deliberately invent traditions to inculcate the ethnic loyalty in the group they seek to secure.

- State institutions perform functions, which can, both advertently and inadvertently, manufacture and/or maintain the ethnic identities of the group(s) that fall within its sovereign authority.

\section{References}

Anderson, B. (1983): Imagined Communities: Reflections on the Origin and Spread of Nationalism (London: Verso)

Brass, P. (1979): 'Elite Groups, Symbol Manipulation and Ethnic Identity among the Muslims of South Asia' in Political Identity in South Asia (eds) D. Taylor \& M. Yapp (London: Curzon Press)

Brass, P. (1991): Ethnicity and Nationalism: Theory and Comparison (New Delhi: Sage)

Collins, P. (2004): 'Black Nationalism and African American Ethnicity: The Case of Afrocentrism as Civil Religion' in Ethnicity, Nationalism and Minority Rights (eds) S. May, T. Modood, \& J. Squires (Cambridge: Cambridge University Press)

Connor, W. (1994): Ethno-Nationalism: The Quest for Understanding (New Jersey: Princeton University Press)

Geertz, C. (1973): The Interpretation of Cultures (London: Fontana)

Gellner, E. (1983): Nations and Nationalism (New York: Cornell University Press)

Grosby, S. (1994): 'Debate: The verdict of history: The inexpungable tie of primordiality - a response to Eller and Coughlan' Ethnic and Racial Studies, 17(1), pp164-171

Gur-Ze'ev, I. (2003): Destroying the Other's Collective Memory (New York: Peter Lang)

Hobsbawm, E. (1983): 'Introduction: Inventing Tradition' in The Invention of Tradition (eds) E. Hobsbawm \& T.

Ranger (Cambridge: Cambridge University Press)

Horowitz, D. ([1985] 2000): Ethnic Groups in Conflict (Los Angeles, CA: University of California Press)

Olson, M. (1965): The Logic of Collective Action: Public Goods and the Theory of Groups (Cambridge, MA: Harvard University Press)

The Star (1961): 18 th January 1961

Van den Berghe, P. (1978): 'Race and Ethnicity: A Sociobiological Perspective' Ethnic and Racial Studies, (1)4, pp401-411

--(1988): 'Ethnicity and the Sociobiology Debate' in Theories of Ethnic and Race Relations (eds) J. Rex \& D. Mason (Cambridge: Cambridge University Press)

--(1995): 'Does Race Matter?' Nations and Nationalism, 1(3), pp357-368

--(2001): 'Sociobiological Theory of Nationalism' in Encyclopaedia of Nationalism (ed) A. Leoussi (London:

Transaction Publishers) 